\title{
Analysis of Difficulties Encountered by Sudanese Basic Level Students in Structuring Compound Sentences
}

\author{
Sawsan Mohamed Ali Mabyou \\ Sudan University of Science and Technology, College of Graduate Studies
}

*Corresponding Author: Sawsan Mohamed Ali Mabyou, Sudan University of Science and Technology, College of Graduate Studies

\begin{abstract}
This study aimed at identifying the difficulties encountered by Sudanese basic level school students who study English as a foreign Language [EFL] face in when they are writing English sentences. Also, The purpose of the study is to find out which of the two sexes can write sentences better( girls or boys) and the exact level of the pupils. It also explores students' strategies used in learning compound sentence writing. In addition, it aims at finding out the role of sentence writing in improving students writing of compositions and essays in general. The researcher used the descriptive analytical approach to investigate this issue. The method used to collect data was two questionnaires: One for the 8th level (translated in Arabic) students at Khartoum locality and the other for teachers of English language, for the academic year (2016). A program using SPSS was applied in the statistical analysis of these two questionnaires. Besides a Cronbach alpha formula was tested and a part of compound sentence writing was added to check the validity and reliability of these two instruments. The statistical results and a sentence writing part reveal that students are weak in writing sentences. The use of old methods in teaching and untrained teachers played role in their weakness but there are some other obstacles, which hinder the writing process. Based on these difficulties, old methods of teaching writing should not be used, teachers should be trained and students are in need of motivated methods in writing compound sentences.
\end{abstract}

Students need to use various writing strategies when writing paragraphs. Some of them are aware of writing rules but the majority of students need more lessons to strengthen their writing ability.

Keywords: Writing Difficulties, compound sentence writing, 8th basic level students, majority of the students.

\section{INTRODUCTION}

Generally, the majority of Arab students face difficulties in learning English (specially writing skills). For example, most students of English as a Foreign Language (EFL) in Sudan face many problems in writing paragraphs. Writing a paragraph seems to be very easy at the beginning. However, students experience serious problems when they write because they do not pay attention to the writing rules. Compound sentences can easily reflect whether or not the learner knows how to put words together to form a correct sentence, to build the second sentence out of the first one and the third out of the second to form a meaningful paragraph which has a unity or coherence. Most of the students find this difficult because they do not know the rules of writing compound sentences including the use of punctuations, conjunctions and prepositions, etc. Students find it difficult to follow the abovementioned rules while writing tests and compositions.

The aim of the current study is to identify the difficulties which encountered by Sudanese secondary school students who study English as a foreign Language [EFL] when they write English compound sentences. The purpose of the study is also to find out which of the two sex can write sentences better (girls or boys) and the exact level of the students.

Writing a single sentence is a measure problem on the way of the Sudanese basic level 8th level, namely because of many problems such as lack of trained teachers to teach the rules and skills of writing, little encouraging of families, the role of the mother tongue on most of the fields ...etc. All these lead to the failure in writing short paragraphs by most students and hence, they never get high marks in their final exams. 
There are many questions that the study has to answer. However, the following are some of them:

1. Why writing meaningful compound sentences become a problem to English language learners at Sahafa basic level schools?

2. What problems face Kharotum Locality in writing compound sentences in English?

3. What type of sex can write English compound sentences better: males or females?

4. What strategies to be adopted to overcome these problems?

In order to answer these questions, the researcher hypnotizes the following:

(1) Writing meaningful compound sentences have been a real problem that faces basic level students, because of the lack of well trained and skillful teachers, using old methods of teaching, little encouraging of families, the role of the mother tongue...etc.

(2) Using the punctuations, capitalizations, conjunctions and writing correct sentences is the most problem that face $8^{\text {th }}$ level basic students in writing compound sentences.

(3) The researcher thinks that females are better than males in writing compound sentences because they are more interested in learning English and have more spare time.

(4) English language teachers have to use the significant methods of writing and follow writing strategies in their teaching.

This study attempts to investigate and explore the obstacles that face Omdurman secondary students in writing compound sentencs perfectly. It also aims to formulate methods and techniques that should be followed by students in order to improve their writing skills. Writing the sentences perfectly must be conveyed by real methods and mechanics.

This study is very important because it shows the weakness of the student performance in writing sentences. It also reflects the necessity of writing in learning English. Although writing compound sentences correctly is the main problem that faces learners, few studies have been written about this issue. So this study will contribute to the improvement of learning English and it is writing skills in Sudan and other Arab speaking countries. It will also help toward improving the curriculum of English language at secondary schools. In addition, it will help students to be creative writers in English language in these countries`.

The study is limited to the problems of writing a compound sentence correctly in Khartoum Locality, $8^{\text {th }}$ level basic schools. It is restricted to six Basic schools. The subjects of the study are male and female students in their final year $\left(8^{\text {th }}\right.$ class). The test consists of punctuations, conjunctions/ prepositions and coherence and cohesion among sentence.

\section{Methodology}

The population of this study are ${ }^{8 \text { th }}$ year basic school students at Sahafa, Khartoum Locality who study English as a school subject for the academic year 2017. The study adopted questionnaires and interviews for data collection and analysis. To apply this, the researcher introduced written test that contains four parts: punctuations, conjunctions and coherence and cohesion among sentences. It is given to students during their normal classes by their own teachers. The test was carried on six schools three for boys and three for girls from various tribes of Sudan. Interviews and questionnaires were used for the data collection. English language teachers were also interviewed. All people interviewed were given pseudonyms for the purpose of confidentiality. As it was mentioned, this study is about difficulties facing Sudanese Basic school Students in Writing sentences. The researchers' argument was that, even though writing is secondary form of language compared to the oral form of it, writing has become a primary form of communication and through it students can strengthen their oral communication skills, because the more they write, the more they excel in vocabulary and grammar, including the rules of writing, more particularly sentence writing which was the main theme of this study. The researcher underscored that writing has become very important means of communication in the current era of globalization, particularly writing in English since English become the first language of communication in business, education and almost all the other fields of human activities. 
The researcher realized that students are experiencing a lot of problems in writing in English since he started teaching English at secondary schools, and thought that the solutions to this problem will be attained by focusing on compound sentence writing which is seen as a bridge between writing sentences and compositions or essays. So the researcher chose it to investigate this problem by carrying his study with students and English teachers in $8^{\text {th }}$ basic level schools in Khartoum. He gave each of the six schools a letter from A to F for privacy reasons. The students were at their final year, three for boys and three for girls. So, as mentioned before the research questions were:

(1)Why writing meaningful compound sentences has become a problem to English language learners at basic level?

(2)What problems face students in writing compound sentences in English?

(3) What type of sex can write English sentences better: males or females?

(4)What are the type of strategies to be adopted to overcome these problems?

With these questions in my mind, the researcher wrote a questionnaire and distributed it to the schools mentioned above. The questionnaire was written into two parts. The first part consisted of eighteen questions, all of which were close ended questions that simply needed true or false answers. The questions were on students' knowledge about rules of writing such as punctuations, capitalizations, transitions, rules of writing compound sentences and other components of grammar. Whereas the question of the second part focused on students' actual knowledge about what they said. I asked them to write ten sentences about themselves. The questionnaire was distributed to about (230) two hundred and thirty students, and received (187) questionnaire papers from the whole number of the students. I also interviewed sixteen English language teachers. These tools had been measured statistically through analyzing all parts.

\section{RESULTS AND DISCUSSION}

The present study uses SPSS program to compute for the results. According to statistical analysis the results are shown as follows regarding students' questionnaire.

Table1. I can write a good academic compound sentence.

\begin{tabular}{|l|l|l|l|l|l|}
\hline \multicolumn{2}{|l}{} & Frequency & Percent & Valid Percent & Cumulative Percent \\
\hline \multirow{3}{*}{ Valid } & True & 94 & 50.3 & 50.8 & 50.8 \\
\cline { 2 - 6 } & False & 91 & 48.7 & 49.2 & 100.0 \\
\cline { 2 - 6 } & Total & 185 & 98.9 & 100.0 & \\
\hline Missing & System & 2 & 1.1 & & \\
\hline Total & 187 & 100.0 & & \\
\hline
\end{tabular}

The results on the table above show that (50.27\%) of the students are able to write a good academic compound sentence, whereas $(48.66 \%)$ of them are not able to do so. The difference between the two results is not so much. This means that teachers should concentrate on teaching the students writing skills. A quick analysis to students' answers showed that what students said about their knowledge on compound sentence writing did not correspond to what they actually wrote. Most of them said that they liked sentence writing, knew how to write sentences, could write a good academic sentences and could logically organize their ideas when they write sentences. However, the researcher discovered (from the sentences they wrote) that most of them wrote poor compound sentences.

In dealing with writing tests in the exam, the analysis reveals that: (see Table 2 below)

Table2. I difficultly pass my writing tests in English.

\begin{tabular}{|l|l|l|l|l|l|}
\hline \multicolumn{2}{|c|}{} & Frequency & Percent & Valid Percent & Cumulative Percent \\
\hline \multirow{3}{*}{ Valid } & True & 105 & 56.1 & 56.5 & 56.5 \\
\cline { 2 - 7 } & False & 81 & 43.3 & 43.5 & 100.0 \\
\cline { 2 - 7 } & Total & 186 & 99.5 & 100.0 & \\
\hline Missing & System & 1 & 5 & & \\
\hline Total & & 187 & 100.0 & & \\
\hline
\end{tabular}


The table above reveals that $(56,1 \%)$ of students can pass their writing tests with difficulty, whereas (43.32\%) are able to pass their tests easily. This result reveals that most of the students are weak in some of the English writing skills because tests examine different parts of writing.

When the researcher interviewed teachers about the solutions, they suggested some of the following solutions:

Firstly, writing should be given especial consideration, because it seems that some of the teachers ignore it. Secondly, teachers should make students write more exercises on sentence and paragraph writing. Thirdly, teachers need to find ways to make students like writing compound sentences (that's to say motivate them). Finally, ministry of education needs to equip schools with new tools for writing such as separate writing books and audio visual aids to motivate writing.

The following extract is from the internet by the title "Time4Writing courses" elementary, middle school paragraph and high school online writing courses.

It presents four important elements which are the secrets to good paragraph writing. The researcher presents them to help learners deal with writing skills in order to write good paragraphs, especially online.

\section{Four EsSential Elements}

Paragraph writing is the foundation of all essay writing, whether the form is expository, persuasive, narrative, or creative. In order to write a good compound sentences, students need to understand the four essential elements of a sentence writing and how each element contributes to the whole. At Time4Writing, a certified teacher acts as an online writing tutor to help students build writing skills by focusing on the fundamentals. And nothing in the writing process is more fundamental than writing a solid sentence. The four elements essential to good paragraph writing are: unity, order, coherence, and completeness. The following example illustrates the importance of these elements in sentences writing.

\subsection{Before \& After Comparison: From a Wandering Sentence to a Wonderful Sentence!}

This example shows how one student approached the writing prompt "What is your favorite day of the week and why?" The original draft has some interesting ideas but overall, the sentence wanders. It includes both relevant and irrelevant details and lacks the coherent focus required for a successful sentence.

In Time4Writing courses, students are taught that the revision process is vital to writing successful sentences. They learn how to use this key step to eliminate unnecessary details and write a tightly structured sentence.

\section{Before - Original Draft}

Sunday is my favorite day of the week. I like it because on Sunday, I watch football. On other days, I also get to watch football but not all day. There are other sports on other days to watch on TV. Sunday lunch is a favorite of mine because I eat with my father in front of the TV. All the other days, I have to eat at the table which is less fun. Some days my dad doesn't make it home from work until after I'm in bed. Some weeks my dad travels, and I don't see him for several days. The highlight of the day is when we watch the Dolphins play. Dad and I get so excited, we yell and cheer together. The thing that I like to do best in the world is watch TV with my dad.

Teacher Observations (Before)

The topic sentence restates the prompt but does not unify the paragraph.

The writer includes several irrelevant details.

The unifying idea in this sentences is that the writer likes Sunday because it gives him/her a chance to be with his/her dad. However, the idea is buried in this draft.

After - Revised Draft

Sunday is my favorite day because I spend the day watching football with my dad. On Sunday, unlike the other days of the week when he works, my dad spends the whole day with me watching football 
on TV. We even eat lunch together while watching. The highlight of the day is watching the Dolphins game. Dad and I get so excited, we yell and cheer together. On Sundays, I get to combine watching my favorite sport and spending time with my favorite person - what a great day!

Teacher Observations (After)

The topic sentence connects the writing prompt with a summary of the main idea.

To keep the paragraph coherent, the most relevant details have been polished, and the others deleted.

The closing sentence summarizes the paragraph and emphasizes the main idea.

\section{REFERENCES}

[1] David, S. Dye, M. (Ed). How to Write a Paragraph

[2] Claude, W.Faulker.(1980) Writing Good sentences.NewYork

[3] Michael McCarthy. (1992) Discourse Analyses for language Teachers,

[4] EJ, Pretorius. ( 2000 ) Applied Linguistics- Reader3 (UNISA),

[5] Peter Mark man, Alison L. Heney., Roberta Markman and Marie L. Waddell.( 2011) 10 Steps in Writing the Research Paper,

[6] TC Jupp and John Milne. A Guided Paragraph Writing

[7] Richards, J. C. and others. (1992). Longman Dictionary of Language Teaching and Applied Linguistics 1992.

[8] Nattinger, J. and J. Deccarico.(1992). 'Lexical Phrases and Language Teaching,

[9] http://write-site. Writing Effective Paragraphs

[10] Oshima, Alice and Ann Hogue (2006) 'Introduction to academic writing' -3rd ed.

[11] https://www.time4Writing

[12] Richard Harrison (1989).'Keep Writing 1,2), Longman Group,U.K

[13] Hyland K (2004) Genre and Second Language Writing. Ann Arbor: University of Michigan Press.

Citation: Sawsan, Mohamed Ali Mabyou. "Analysis of Difficulties Encountered by Sudanese Basic Level Students in Structuring Compound Sentences." International Journal of Humanities Social Sciences and Education (IJHSSE), vol 4, no. 10, 2017, pp. 54-58. doi:http://dx.doi.org/10.20431/2349-0381.0410007.

Copyright: () 2017 Authors. This is an open-access article distributed under the terms of the Creative Commons Attribution License, which permits unrestricted use, distribution, and reproduction in any medium, provided the original author and source are credited. 